\title{
Cantillon e Sismondi sobre população, renda e subsistência
}

\author{
MAURICIO C. COUTINHO*
}

Cantillon and Sismondi on population, revenue and subsistence. The paper compares Cantillon's and Sismondi's views on population, revenue and wage of subsistence, having Malthus' law of population as a background. We assume that the XVIII and XIX century controversies on population and economic development provide a good framework for a reappraisal of economics in general, including value and distribution. In our perspective, both Cantillon and Sismondi cannot be put under the umbrella of the Ricardian (or Sraffian) approach to wage and distribution.

Key-words: Cantillon; Sismondi; wages; subsistence; revenue

JEL Classification: B11

\section{INTRODUÇÃO}

O artigo discute as relações entre população e economia na obra de Richard Cantillon e Sismonde de Sismondi, autores que compartilharam com Malthus a concepção de que o tamanho da população é uma função da disponibilidade de meios de vida, e de que a atividade agrícola ocupa um papel especial no sistema econômico. Veremos que, a despeito dos pontos em comum, Cantillon e Sismondi afastaram-se da lei malthuseana de população em dois aspectos cruciais: na análise dos mecanismos de ajustamento entre população e meios de vida, e na adesão a uma perspectiva populacionista. Esse afastamento levou a uma visão contrastada sobre as relações entre economia e população, com desdobramentos importantes no entendimento da natureza do excedente econômico e na visão da economia, de modo geral.

Acredito que as passagens do Essay on the Nature of Commerce in General, de Cantillon, e dos Nouveaux Príncipes d'Économie Politique, de Sismondi, on-

\footnotetext{
* Professor titular da Universidade Estadual de Campinas — UNICAMP. E-mail: mcout@eco.unicamp.br. Submetido: julho 2005; aceito janeiro 2006.
} 
de as relações entre população e economia estão mais bem estabelecidas, são aquelas que tratam da renda da terra e do salário de subsistência. O artigo proporá que, em particular na fixação do salário de subsistência, Cantillon e Sismondi distanciaram-se do padrão clássico (ou ricardiano), o que tem impactos na determinação da relação entre produção e excedente. Nessa perspectiva, nas visões sobre população e fixação dos salários ao nível de subsistência, afloram no "Ensaio" e nos "Novos Princípios" elementos não-clássicos (ou não-ricardianos). ${ }^{1}$

Entendo que os tópicos abordados - população, subsistência, renda da terra - oferecem um ângulo privilegiado para a discussão dos temas centrais da economia política dos séculos XVIII e primeira metade do XIX, inclusive valor e distribuição. Sob esse ponto de vista, pode-se dizer que o artigo efetua, a partir da temática da população, uma incursão lateral ao núcleo da economia política clássica, tangenciando uma questão mais ampla: em que medida é lícito supor a dominância, até John Stuart Mill, de um "sistema de economia política clássica", entendido como uma imagem do sistema ricardiano? ${ }^{2} \mathrm{O}$ foco na noção de salário de subsistência e na dinâmica populacional — um tema importante em si e caro aos economistas dos séculos XVII, XVIII e XIX — pode, desse modo, ser considerado instrumental, já que proporciona acesso às visões contrastadas dos economistas em torno de diversos outros tópicos. À medida que Malthus, por razões bem conhecidas, é o autor de referência em questões populacionais, suas idéias permanecerão como uma espécie de pano de fundo de toda a argumentação.

O artigo compõe-se, além desta introdução, de seções que abordam a relação entre população e meios de vida em Cantillon; a concepção de riqueza e as relações sociais na agricultura em Sismondi; salário de subsistência e excedente econômico; renda da terra. A conclusão, finalmente, propõe uma síntese e aponta algumas das perspectivas abertas pela discussão sobre população e excedente.

\section{CANTILLON: O AJUSTAMENTO ENTRE POPULAÇÃO E MEIOS DE VIDA NO ÂMBITO DE UMA ECONOMIA NATURAL}

"Quando os meios de subsistência são ilimitados, os homens multiplicam como ratos no celeiro." (Cantillon, 1755:37) Essa frase, que antecede a passagem do Ensaio sobre a Natureza do Comércio em Geral, em que Cantillon chega à conclusão de que a população inglesa nas colônias cresce muito mais rapidamente do que na Inglaterra por defrontar-se com disponibilidade ilimitada de terras para cultivo, fornece uma sugestiva confirmação à tese de que o contingente populacional é função dos meios de subsistência.

\footnotetext{
${ }^{1}$ Em relação às implicações do mecanismo de determinação dos salários sobre o sistema ricardiano como um todo, acompanhamos a interpretação clássica de Sraffa (1951). Retornaremos ao tema nas conclusões.
}

${ }^{2}$ A expressão "sistema de economia política clássica” é utilizada, entre outros, por Cartelier (1981). 
Cantillon entende que a população é um fator de riqueza, o que nos autoriza a incluí-lo no rol dos autores populacionistas. ${ }^{3}$ Uma abordagem mais detalhada do Ensaio, no entanto, revela que os nexos entre o tamanho da população e o nível de riqueza são bastante complexos, passando por um entendimento do papel atribuído aos hábitos de subsistência e à possibilidade de obtenção de excedente econômico a partir da exploração agrícola.

O quadro de referência do Ensaio transparece na comparação entre dois países em situação bem distinta, a China e a Inglaterra. Para Cantillon (como para Adam Smith), a China atingiu o topo em riqueza e estagnou. A situação não é de miséria e o país consegue manter uma população numerosa, graças aos hábitos de consumo frugais - os camponeses se mantêm com uma ração exígua de arroz - e à fertilidade da terra.

$\mathrm{Na}$ Inglaterra, como nos demais países avançados da época, a cesta de consumo é bem mais diversificada. A geração de excedente, bem como o crescimento da população, requerem a incorporação de uma proporção elevada do território ao cultivo de cereais. A sustentação de uma população numerosa depende da produção de alimentos e/ou da exportação de manufaturas em troca de produtos agrícolas.

Considerando-se a relação social de arrendamento, o modelo de produção de alimentos e de expansão populacional do Ensaio encadeia-se do seguinte modo:

1. As decisões dos proprietários determinam o nível de utilização da terra e a área total destinada à produção de alimentos. Essas decisões envolvem tanto o que fazer com a terra - deixá-la inculta, preservar bosques, criar cavalos, destinar áreas ao plantio de cereais — quanto os hábitos de consumo, que influenciarão os gostos da população e poderão, inclusive, provocar um excesso de importações. Deve-se assinalar que as decisões dos proprietários são apenas parcialmente orientadas por sinais de mercado (preços relativos dos diversos bens e valor da renda) e fortemente influenciadas por suas preferências de lazer e consumo. ${ }^{4}$

2. Dada a produtividade da terra, as decisões dos proprietários determinam o produto agrícola bruto, bem como o nível de emprego na agricultura e nos demais ofícios. Determinam também o tamanho da população.

3. Dado o nível de subsistência dos trabalhadores agrícolas, que é definido por hábitos sociais e representa o principal custo de produção, o produto bruto determina a renda da terra (a "primeira renda") e os lucros dos fazendeiros (a "terceira renda").

A distribuição da população no território e a própria organização da rede urbana são produtos do mesmo encadeamento. Não se trata apenas de conside-

\footnotetext{
${ }^{4} \mathrm{O}$ título do capítulo XIV da Parte I do Ensaio é: "As fantasias, as modas e os modos de vida dos príncipes, e especialmente dos proprietários de terra, determinam o uso que é dado à terra em um estado" (Cantillon, 1755: 27).
} 
rar que as atividades trabalho-intensivas resultam em maior volume de emprego. ${ }^{5}$ Se essa conclusão é fundamentalmente correta, ela quase inverte a ordem do raciocínio de Cantillon, que é a seguinte: emprego elevado (na agricultura e na manufatura) requer a disponibilidade de alimentos e, portanto, de terras destinadas ao seu cultivo e/ou de capacidade de importação.

A bem conhecida ilustração sobre a troca de renda belga por vinho francês, que abre a Parte III do Ensaio e apóia toda a argumentação sobre comércio internacional, é bastante sugestiva. Cantillon conclui que os belgas destinarão uma área elevada à produção de subsistência, uma vez que a manufatura de renda (e não o cultivo de linho) absorve muitos trabalhadores, os quais têm de ser alimentados. Já os franceses subtrairão terra do cultivo de alimentos ao dedicarem áreas extensas aos vinhedos e às pastagens necessárias ao pastoreio dos cavalos utilizados no transporte da produção vinícola. Os franceses vêem-se prejudicados por diversas razões: a produção de vinho é intensiva em mão de obra e ocupa terras que poderiam ser dedicadas aos cultivos de subsistência; o vinho é trocado por um produto que não se destina à subsistência; trata-se de uma atividade intensiva em transporte e que, em decorrência disso, leva à ocupação do território com pastagens.

Cantillon entende que a troca de renda por vinho, mesmo implicando uma equivalência monetária, é prejudicial aos franceses, que perdem capacidade de sustentação da população por subtraírem terras do cultivo de alimentos. Os belgas não só preservam a capacidade de produção de alimentos como obtêm a vantagem suplementar de cultivar alimentos nas terras anteriormente destinadas ao plantio de cevada, ao substituírem o consumo de cerveja por vinho.

O encadeamento exposto acima - da decisão dos proprietários à população ocupada e à renda líquida - supõe uma dada tecnologia. Anteriormente nos referimos a cultivos mais ou menos trabalho-intensivos, mas poderíamos ter considerado a questão da tecnologia de modo amplo, como Tarascio (1991). ${ }^{6}$

A ilustração habitualmente referida para enfatizar a importância da cultura e da tecnologia no tamanho da população é a dos povos que vivem da caça. Conforme Cantillon, os índios norte-americanos necessitam de uma área extensa para sustentar uma população exígua porque a caça é um meio de vida que implica uma relação elevada entre território e população. Civilizações agrícolas conseguem manter uma população muito maior em território menor.

Há argumentos para se sustentar que o exemplo dos índios norte-americanos é extremo e pouco representativo. A rigor, se Cantillon está ciente de que sistemas de produção e tecnologias de cultivo, e até mesmo as diferentes aptidões naturais dos solos, condicionam a capacidade de sustentação da população, ${ }^{7}$ no

\footnotetext{
${ }^{5}$ Como fazem Brewer (1992) e Tarascio (1991).

6 "Em resumo, para Cantillon, tamanho e distribuição da população são função da dotação de recursos, fatores culturais e tecnologia”. (Tarascio, 1991).

${ }^{7}$ Isso se pode inferir de afirmações como: "Se as terras são apropriadas apenas para a manutenção de ovelhas, como nos distritos arenosos e campos de pastos, as vilas serão poucas e pequenas,(...) ." (Cantillon, 1755:8)
} 
geral essas questões ocupam um papel de pequena relevância em sua obra e vêemse ofuscadas pela preocupação - esta sim decisiva - com os custos de transporte. Pela mesma razão, as rendas diferenciais de fertilidade não integram o sistema de Cantillon, enquanto a renda diferencial estritamente locacional (devida a transporte) recebe um tratamento exclusivo.

A própria recomendação de espalhar as atividades manufatureiras pelo território, à qual Cantillon chega ao discutir os meios de nivelar a circulação monetária, coaduna-se com esta perspectiva: onde estiver a população, teremos produção de subsistência. A população orienta-se pela demanda por mão-de-obra; no caso, uma demanda condicionada pela nova localização de atividades, induzida por diferenciais de custo de transporte. Para que a população sobreviva, tem de haver produção de alimentos. Vantagens naturais na produção dos diversos produtos agrícolas são praticamente desconsideradas. Aliás, até mesmo no elaborado exemplo da troca de renda belga por vinho francês, em nenhum momento evocam-se as vantagens comparativas naturais.

No que se refere aos mecanismos de ajustamento entre população e meios de vida, os argumentos de Cantillon são muito mais brandos do que os que viriam a caracterizar a obra de Malthus. Para começar, não existe impedimento absoluto ou agronômico à manutenção da população. A China é o exemplo mais eloqüente de que uma combinação entre técnicas eficientes e subsistência frugal pode prover meios de vida a uma população numerosa.

Além disso, pode-se dizer que no Ensaio o ajustamento entre população e meios de vida é absolutamente dominado por aquilo que Malthus (1803) denominaria de preventive checks. Cantillon concede uma grande importância à aspiração de todo ser humano a assegurar para os filhos uma posição social no mínimo igual a sua. Essa aspiração é suficiente para fornecer um roteiro moral que leva à postergação de matrimônios e/ou ao celibato; enfim, funciona como um eficiente instrumento moral de controle de natalidade.

Finalmente, a migração atua como um dos meios mais eficazes de ajustamento entre população e meios de vida. Os ajustamentos no mercado de trabalho por migração aplicam-se tanto à população rural quanto à urbana e, ao menos no que se refere às ocupações manufatureiras, aos planos nacional e internacional. ${ }^{8}$ Sempre que o mercado de uma comunidade revelar-se insuficiente para atender aos trabalhadores com determinada qualificação, ocorrerá emigração. À medida que os pais preparam os filhos homens para o exercício das atividades nas quais têm experiência, o encurtamento das oportunidades, provocado por retrações do mercado ou pela simples sobrevivência de um número de filhos acima da capacidade de absorção do mercado local, leva à emigração. De modo

\footnotetext{
${ }^{8}$ Ao discutir a relação entre preços e meio circulante, Cantillon afirma que, quando a elevação de preços diminui a competitividade de um país, “(...) muitos dos trabalhadores e mecânicos que vêem o trabalho diminuir, abandonam o estado para encontrar mais trabalho nos países com as novas manufaturas." (Cantillon, 1755: 75).
} 
simétrico, novas oportunidades ativam o mecanismo de elevação dos salários e atraem trabalhadores.

Em suma, se existe uma relação de fundo entre meios de vida e população, o ajustamento dá-se de modo suave, em parte orientado pelos sistemas de incentivos e pelos mecanismos de mobilidade, em parte por hábitos que se transmitem de geração a geração. Não se deve esquecer que o elo inicial na cadeia - o que de fato determina o tamanho da população - são as decisões de consumo e de utilização do solo dos proprietários, os que formam a "classe independente", ou o único cuja posição social permite uma efetiva autonomia nas decisões.

\section{SISMONDI, RIQUEZA E RELAÇÕES DE PRODUÇÃO NA AGRICULTURA}

Para Sismondi, o bem estar do homem — de todos os homens - representa o objeto da economia política e o suposto propósito dos governos. Sendo a riqueza aquilo que satisfaz as necessidades físicas dos homens, a riqueza nacional não é algo passível de uma mensuração absoluta; o que interessa é a relação entre a riqueza nacional e a população ou, dito de outro modo, à medida que a todos os habitantes é dado o usufruto dos bens que proporcionam conforto e felicidade. ${ }^{9}$

O populacionismo de Sismondi afirma-se no interior desse quadro. A população é uma vantagem, desde que "(...) cada homem esteja certo de encontrar pelo trabalho uma existência honesta" (Sismondi, 1819:65), o que envolve uma certa distribuição da riqueza nacional e uma adequação entre o contingente populacional e os meios de subsistência. A defesa da propriedade privada situa-se no mesmo contexto, vale dizer, ela é útil porque induz ao trabalho e favorece a multiplicação da riqueza, desde que se assegure “(...) a todo trabalho sua recompensa”.(Sismondi, 1819:66).

O excesso de população enfraquece as condições de barganha dos trabalhadores e leva à espoliação. Na visão de Sismondi, a espoliação corresponde a uma remuneração do trabalho abaixo de seu custo, o que assegura ao capitalista um lucro acima do ordinário. Porém, mesmo em condições normais, a troca entre capitalistas e trabalhadores é desigual, porque a concorrência leva a que o trabalhador fique apenas com o necessário “(...) para manter sua vida” (Sismondi, 1819:119), enquanto o capitalista retém o restante da renda criada pelo trabalho. Se a renda do capitalista for dissipada ao invés de acumulada, a queda na demanda por trabalho levará os salários a um nível inferior ao de subsistência e a uma diminuição da população. O decréscimo da população é uma decorrência natural da miséria.

No sistema de Sismondi, o ajustamento entre população e meios de vida é

\footnotetext{
9 "Não é o caso, de um modo absoluto, que a riqueza e a população sejam os signos da prosperidade dos estados; são apenas em relação uma com a outra." (Sismondi, 1819:65).
} 
mediado por dois fatores. Em primeiro lugar, pela magnitude do lucro, a qual depende do nível de subsistência e das condições de oferta e demanda nos mercados de trabalho. Em segundo lugar, pela proporção acumulada do lucro, que determina a expansão da produção e a demanda por trabalho. Em condições salariais favoráveis, a população inexoravelmente cresce, porque a mortalidade infantil cai e aumenta o número de casamentos. ${ }^{10}$ À primeira vista, uma combinação de preventive checks e positive checks, ao estilo de Malthus, produz o ajustamento entre população e meios de vida.

$\mathrm{Na}$ realidade, nos Novos Princípios esse ajustamento se processa no interior de um sistema de certa complexidade, no qual a análise da dinâmica populacional situa-se em um contexto bastante original e diverso do malthuseano. Três elementos desse sistema merecem menção especial: a preocupação com o bem-estar de toda a população; o marco de referência do fluxo circular de produção e de rendimentos, e das mudanças de forma do capital; a percepção sócio-institucional das relações sociais, e sua interação com o movimento da economia. Vamos tratar brevemente de cada um desses elementos, concentrando a atenção na dinâmica populacional.

A preocupação com o bem-estar da população é inerente, como foi visto, ao próprio conceito de riqueza nacional. Para Sismondi, a renda per capita é um indicador de riqueza muito mais preciso e relevante do que a renda absoluta. Como o trabalhador é a parte frágil da estrutura social, o risco de que a parcela que lhe cabe do produto seja pequena e/ou de que o próprio nível de produção permaneça aquém do necessário para assegurar a todos o acesso à subsistência, é um tema dominante nos Novos Princípios.

Neste ponto, o sistema de Sismondi mescla a distribuição do produto social com a determinação do nível de produção. Enquanto para Ricardo uma taxa de lucro elevada é garantia de acumulação acelerada e, portanto, de uma pressão de demanda no mercado de trabalho que acabará produzindo mecanismos de ajustamento entre população e meios de vida de estilo malthuseano, para Sismondi a taxa de lucro elevada não é garantia de acumulação acelerada - um ponto ao qual voltaremos a seguir. Mais ainda, a relação entre renda do trabalho e produto social é flexível e capaz, ela própria, de influenciar o nível de produção. Em suma, não só inexiste uma independência estrita entre produção (valor) e distribuição - outro ponto ao qual voltaremos - como a geração de riqueza recebe estímulos positivos e negativos, conforme a particular forma das relações sociais. Um dos aspectos fundamentais dos Novos Princípios é a pregação a favor de relações sociais que sejam, simultaneamente, produtivas ao favorecerem os lucros e a acumulação do capital, e protetoras da população pobre.

A idéia de que a riqueza executa um movimento circular, que envolve circu-

10 "Desde que cesse a miséria, as crianças que morreriam em idade jovem vivem para usufruir desta nova abundância; os celibatários (...) casam-se para aproveitar a demanda por trabalho". (Sismondi, 1819:66). 
lação e, portanto, mudanças de forma, é outro dos elementos dominantes do sistema. Para Sismondi, o rendimento nacional regula a despesa nacional, a qual, em situações expansivas, deve corresponder à totalidade da produção. Quando a despesa não corresponde à produção, a riqueza não se expande. Ora, se assumirmos que os salários tendem a ser totalmente despendidos, os lucros passam a representar a variável estratégica. Os lucros podem não ser utilizados de modo a propiciar a expansão da riqueza nacional, condição que interrompe o ciclo consumo-rendimentos que caracteriza o equilíbrio com expansão.

A interrupção do ciclo consumo-rendimentos ocorre em diversas circunstâncias: produção de produtos não-vendáveis; excesso de consumo não-reprodutivo; endividamento excessivo dos capitalistas (e excesso de consumo não-reprodutivo). Todas essas circunstâncias têm o potencial de exercer impactos negativos sobre os lucros. Enfim, o circuito reprodutivo pode ver-se perturbado por simples desajustes entre oferta e demanda ou por atitudes que tolhem a acumulação de capital. Em qualquer situação, a queda dos lucros decorrente da retração do produto será antecedida por perturbações no mercado de trabalho, as quais produzirão desemprego e miséria.

O papel das relações sociais na expansão da riqueza fica bem estabelecido no Livro Terceiro dos Novos Princípios, que trata da riqueza territorial. Nesse Livro, a discussão sobre a renda da terra é precedida por um amplo painel sobre as relações de produção no campo, cuja importância é tanto maior por sabermos que Sismondi, como Cantillon, devota uma atenção especial às "riquezas que provêm da terra" (Sismondi, 1819:148). Vale lembrar que a produção agrícola ocupa um papel especial por ser a responsável pela subsistência e por representar, ainda no século XIX, a principal fonte de emprego.

Sismondi considera que o rendimento da terra é composto de rendimento líquido (renda da terra mais lucros dos adiantamentos primitivos), lucro e "reprises" (o que repõe a subsistência dos trabalhadores e os demais adiantamentos anuais). Enquanto os proprietários interessam-se apenas pela parcela que obtêm a título de rendimento líquido, à nação interessa a totalidade dos rendimentos da terra ou o rendimento bruto. Pode haver crescimento do produto líquido às expensas do produto bruto. Pode ocorrer, por outro lado, expansão do produto bruto com queda da riqueza per capita. Para Sismondi, trata-se de estimular os sistemas produtivos que provocam expansão de todos os rendimentos, algo intimamente associado às relações sociais de produção na agricultura ou, se quisermos, às formas institucionais em que se processa a exploração agrícola.

No Livro Terceiro, Sismondi efetua uma ampla digressão sobre as diversas relações sociais de produção no campo, em existência ou historicamente conhecidas: exploração patriarcal, servidão, meação, corvéia, arrendamento. No fundamental, o Livro Terceiro examina os incentivos ao aumento da produção, bem como as condições de vida dos trabalhadores nos diferentes sistemas de exploração agrícola. No caso do arrendamento, que é a relação moderna, Sismondi coteja as virtudes e deméritos da pequena e da grande exploração, e constata que na última emerge um nexo suplementar no sistema de incentivos, envolvendo o 
arrendatário e os trabalhadores. Na grande exploração, a situação dominante do fazendeiro no contrato de trabalho estimula-o a expandir os lucros, em detrimento dos salários.

Sem deixar de enfatizar o pioneirismo da análise econômica institucional de Sismondi, o importante aqui é assinalar que a minuciosa descrição das modalidades de exploração agrícola confirma algumas das características gerais do sistema: a atenção ao bem-estar e à adequada disponibilidade de meios de vida, a preocupação com a expansão da produção e, sobretudo, o reconhecimento de que tanto o nível de produção quanto a relação subsistência/excedente são elásticas e reciprocamente determinadas.

Nessa medida, a análise do fluxo circular da renda distancia-se bastante do quadro razoavelmente estático em que fora estabelecida por Cantillon e pela fisiocracia. Pode-se dizer que se aproxima de uma visão que, em sua dupla dimensão, só Marx viria a desenvolver: mudanças da forma de capital ao longo do circuito reprodutivo e a consideração de que a relação entre trabalho excedente e necessário é elástica, o que afeta tanto a distribuição de renda quanto o próprio nível do produto social.

\section{SUBSISTÊNCIA E EXCEDENTE ECONÔMICO}

O sistema de Cantillon gira em torno da renda da terra e das disposições dos proprietários. A renda é a parcela do produto agrícola que fica à disposição do proprietário, uma vez assegurada a manutenção dos trabalhadores e dos fazendeiros que os empregam. A renda é, portanto, em uma primeira aproximação, um excedente sobre os meios básicos de vida das pessoas necessárias ao cultivo da terra.

Ao se referir à determinação dos meios de vida dos trabalhadores e empregadores rurais, o Ensaio é genérico. Expressões como "meio de vida", "comida e manutenção" indicam apenas que, para obter-se o produto agrícola (e a renda), a "primeira necessidade" é assegurar a subsistência dos que trabalham na terra. Como vimos anteriormente, a população total empregada dependerá das decisões dos proprietários. Assim, ao tratar da subsistência, o que Cantillon pretende é mostrar que, sejam quais forem as decisões de produção, uma parte da área cultivada e do produto da terra obrigatoriamente será destinada à produção de meios de vida dos trabalhadores necessários àquela produção.

O Ensaio é pouco específico quanto à exata determinação desses meios de vida, por diversas razões. Em primeiro lugar, a maior parte das observações sobre a subsistência no campo está contida em um capítulo particular, o XI da Parte I, que trata da medida de valor, ou do "par terra-trabalho". Na intrincada discussão sobre medida de valor, o foco da atenção é a quantidade de terra que deve estar à disposição de uma família trabalhadora para que ela possa se reproduzir, considerando-se as diversas composições familiares e as diversas modalidades de utilização do solo. Em suma, o objetivo dessas passagens é estabelecer o par ter- 
ra-trabalho, ou a medida de valor, algo que depende do padrão de subsistência, mas não envolve, neste contexto teórico, uma discussão mais aprofundada sobre os determinantes da cesta de subsistência.

Em segundo lugar, ao tratar da população agrícola, Cantillon considera a subsistência de duas classes, os trabalhadores e os arrendatários, incluindo os respectivos familiares. Naturalmente, os arrendatários têm acesso a uma renda maior e a condições de vida mais folgadas. Embora grande parte dos fazendeiros obtenha apenas o necessário a sua subsistência, uma pequena parcela consegue prosperar. Como os mestres-artesãos, os fazendeiros são "empresários trabalhando a risco" (Cantillon, 1755:20), e podem ser bem sucedidos. Cantillon considera que sua subsistência será dupla nesse caso. Assim, mesmo no campo, há uma diversidade de condições de subsistência: arrendatários mais ou menos bem-sucedidos, trabalhadores com maior ou menor responsabilidade, famílias de tamanho e capacidades de trabalho diversas...

Finalmente, é importante estabelecer uma linha de demarcação entre ocupações rurais e urbanas. Os artesãos manufatureiros também vivem de subsistência, embora sejam muitas vezes "empresários trabalhando a risco". A subsistência nas cidades é necessariamente mais cara, já que há custos de transporte a serem considerados. De todo modo, nas cidades moram os proprietários, os funcionários públicos e os trabalhadores qualificados, pessoas mais abonadas e que têm, na visão de Cantillon, uma subsistência maior.

Por outro lado, a remuneração dos trabalhadores manufatureiros envolve não somente os custos de alimentação e abrigo, no sentido estrito. Cantillon considera ainda os custos de qualificação da mão-de-obra, os riscos referidos à segurança do trabalho e até mesmo os riscos dos mercados de trabalho e de produtos. Estes últimos são amplos o suficiente para abranger ocorrências como a obtenção ou não de ocupação contínua e flutuações dos preços dos produtos vendidos pelos produtores/trabalhadores. Enfim, esses custos são em parte prospectivos - envolvem estimativas dos pais no momento da formação dos filhos - e aproximam-se mais da noção de custo de oportunidade do que de custos incorridos. Se somarmos isso ao fato de nas ocupações urbanas a renda do trabalho confundir-se com a renda do capital, é razoável considerar-se que a remuneração de subsistência dos trabalhadores urbanos aparece no Ensaio como uma idéia bastante ampla ou até mesmo fluida.

Convém observar, contudo, que, a despeito da fluidez conceitual, a remuneração dos trabalhadores urbanos não interfere na determinação da renda da terra, uma vez que a quase totalidade dos custos de produção na agricultura está referida a produtos agrícolas.

No sistema de Sismondi, a determinação dos salários ocupa um papel de destaque, pois a mão-de-obra é considerada o elemento mais importante do "preço do produtor". A referência a "preço do produtor" é sugestiva. Sismondi deseja contrapor o "preço médio de mercado" (preço de demanda) ao preço de custo (preço de oferta do produtor), de modo a estabelecer como se distribuem os rendimentos entre os fabricantes e os mercadores. O preço da mão-de-obra funcio- 
na como um regulador do "preço do produtor", pois o salário de subsistência representa um piso. Já os outros elementos do "custo do produtor", os juros e os lucros, não têm a mesma inflexibilidade.

A inflexibilidade do preço da mão-de-obra atua no médio prazo, e apenas no sentido descendente: existe um mínimo de subsistência. Isso não impede que a remuneração do trabalho possa propiciar ao trabalhador o acesso ao supérfluo, situação em que o salário real - medido em mercadorias comandadas será mais elevado. Sismondi considera auspiciosa a elevação do salário dos trabalhadores, pois “(...) assegurar a sua felicidade é tornar feliz a grande massa da nação." (Sismondi, 1971 [1819]:273)

A regra geral, no entanto, é o trabalhador reter do produto social o estritamente necessário à subsistência, o que decorre da natureza do intercâmbio entre o capital e o trabalho em condições de oferta abundante de mão-de-obra. No limite, condições salariais favoráveis produzirão um impacto sobre a oferta de trabalho, realimentando o mecanismo de fixação dos salários ao nível de subsistência.

Quanto ao que determina o nível de subsistência, Sismondi é pouco específico. Nas passagens que avaliam as condições que levam o trabalhador à miséria e produzem o decorrente ajustamento populacional, o texto dos Novos Princípios sugere a conclusão de que o nível de subsistência representa um simples mínimo fisiológico. Contudo, o detalhado relato da riqueza territorial (Livro Terceiro) mostra que as diversas relações sociais na produção agrícola proporcionam níveis variados de conforto ao trabalhador. Proporcionam também, conforme anteriormente mencionado, um maior ou menor produto bruto, o que depende fundamentalmente dos sistemas de incentivos inerentes aos arranjos institucionais. Podemos ter aumento simultâneo do produto bruto e líquido, ou seja, um estado em que o crescimento dos rendimentos permite a elevação concomitante do salário real (em mercadorias) e da produção excedente.

É lícito concluir do estudo da riqueza territorial que as relações sociais no campo, sendo duradouras, convertem os padrões de subsistência a eles associados, em normas sociais. Assim, admite-se em tese que o padrão de subsistência no campo pode escapar em caráter permanente do mínimo fisiológico.

As passagens dos Novos Princípios que abordam o trabalho manufatureiro têm um tom bem mais cético. Nesse caso, como se viu, a oferta abundante de mão-de-obra conspira contra os trabalhadores, reduzindo os salários ao mínimo fisiológico. Menos do que um contraste entre as condições de vida na cidade e no campo, acredito que estamos diante de planos distintos de análise. Em uma situação, trata-se de avaliar a natureza do conflito entre capital e trabalho; na outra, de considerar as possibilidades de expansão da riqueza abertas pelos diversos arranjos institucionais compatíveis com a exploração agrícola. ${ }^{11}$ Também

\footnotetext{
${ }^{11}$ Cantillon, ao contrário, não tinha dúvida de que os trabalhadores da cidade ganhavam mais do que os do campo, o que se devia à complexidade de suas ocupações e a sua natureza mista e quasecapitalista.
} 
pode haver conflito entre capital e trabalho no campo, mas ele não é necessariamente dominante, e nele o trabalhador nem sempre entra com condições de barganha precárias.

\section{SUBSISTÊNCIA E RENDA DA TERRA}

Para Cantillon, a renda da terra é o excedente à disposição do proprietário, uma vez assegurados os meios de vida dos trabalhadores e arrendatários. A determinação desse excedente é importante, e não somente porque dele vivem os proprietários, a classe que por direito natural ocupa o papel nuclear na ordem social e de cujas decisões depende o funcionamento da economia. É importante porque seu valor é a base para a determinação da quantidade de dinheiro em circulação, um fator crucial em uma obra que trata, sobretudo, da circulação monetária e de seus impactos sobre os preços e as transações internacionais.

Rigorosamente, a renda da terra no sistema de Cantillon é determinada em termos físicos. O valor da renda dependerá do nível geral de preços ou, numa primeira instância, do preço dos bens agrícolas. O montante da renda, em termos físicos, depende de diversos fatores, entre os quais as decisões de utilização de solo do proprietário, os hábitos de subsistência, a capacitação do arrendatário e os sinais de mercado por ele recebidos.

A constatação de que a renda representa, de modo geral, um terço do valor da produção, é um elemento de experiência. Em alguns países essa proporção é excedida, mas Cantillon considera que, quando isso ocorre, os fazendeiros são muito pobres. ${ }^{12}$ Fazendeiros pobres não conseguem obter da terra uma produção elevada, enquanto os fazendeiros que têm "(...) algum capital para tocar os negócios de sua fazenda(...)" (Cantillon, 1755:52) obtêm melhores resultados e representam um risco menor para o proprietário.

Nesse ponto, revela-se mais uma vez o preço alto que Cantillon paga por seu sistema permanecer preso à circulação monetária. Não se extraem conseqüências nem se examinam as implicações econômicas dos diversos graus de capitalização dos fazendeiros, uma vez que a atenção é logo dirigida a questões monetárias, como o nível de preços, a quantidade de dinheiro em circulação, a relação entre preços e taxa de câmbio.

O mesmo ponto de referência dominantemente monetário tolhe a análise dos diferenciais de produtividade e dos usos alternativos do solo, dadas as capacitações naturais. Cantillon admite a existência de uma renda diferencial de localização, mesmo porque os custos de transporte são um elemento essencial de seu modelo de circulação monetária. ${ }^{13}$ Não desenvolve a idéia de uma renda diferencial

\footnotetext{
${ }^{12}$ Cantillon refere-se ao estado de Milão e também à China: "Eu não duvido que o proprietário de terras chinês extraia de seu fazendeiro mais do que três quartos do Produto(...)” (Cantillon, 1755:51).

${ }^{13}$ Esse ponto foi desenvolvido em Coutinho (2005).
} 
associada às capacitações naturais do solo. Como vimos anteriormente, diferenças naturais nem mesmo parecem representar um fator determinante do tamanho da população e até mesmo de sua distribuição no território.

Para Sismondi, o rendimento periódico da terra subdivide-se em três partes. A primeira abrange os juros líquidos do capital primitivo, além de uma parcela “(...) destinada a pagar ao proprietário a assistência que a terra doa ao trabalho humano(...)" (Sismondi, 1819:147). A segunda retribui todos os adiantamentos efetuados, inclusive a subsistência dos trabalhadores. A terceira parte, finalmente, corresponde aos lucros do capital do fazendeiro. A relação entre esssas partes não é fixa e, como vimos, o Livro Terceiro dos Novos Princípios mostra que existem arranjos sociais que permitem elevar os rendimentos brutos e líquidos, assim como há outros que inibem a produção. Além disso, a regra de que os preços e rendimentos são determinados por oferta e demanda, atua também na formação do valor dos componentes da renda bruta da terra, de modo que são diversas as combinações possíveis: a renda dos trabalhadores pode subir às expensas dos lucros do fazendeiro; os lucros, às expensas da renda do proprietário etc.

$\mathrm{O}$ arrendamento, uma forma jurídica típica das nações mais desenvolvidas, é apenas uma das relações sociais em que se dá a exploração agrícola. Se de um lado o arrendamento favorece a aplicação da ciência à agricultura e mostra-se capaz de estimular fazendeiros e trabalhadores, pode, de outro, levar à concentração dos capitais e à criação de uma classe de trabalhadores agrícolas pobres. $\mathrm{Na}$ medida em que o arrendatário capitalista expande os lucros tanto com a elevação do preço dos produtos quanto com a compressão da renda dos proprietários e dos salários dos trabalhadores, o arrendamento gera um conflito especial entre trabalhadores e fazendeiros, a se somar ao conflito entre capitalistas e arrendatários. Conforme Sismondi, as grandes explorações agrícolas concentram o poder em favor dos proprietários e levam a uma contratação salarial desfavorável aos trabalhadores. Nas grandes propriedades em regime de arrendamento, a figura do trabalhador agrícola pobre é uma realidade.

Enfim, ao tratar do arrendamento, Sismondi está atento aos conflitos entre trabalhadores e capitalistas, aos conflitos entre proprietários e capitalistas, sem desconsiderar o conflito com os consumidores, cujo bem-estar depende da abundância das provisões a preços baixos.

Do ponto de vista da teoria econômica da renda, um dos focos dos Novos Princípios é a crítica das concepções de Ricardo. As objeções de Sismondi a Ricardo coincidem em linhas gerais com as desenvolvidas por Malthus no Principles of Political Economy (1820) e podem ser resumidas a alguns pontos, que permitem um melhor entendimento de sua visão de economia agrícola:

- Ricardo pressupõe uma taxa de lucro uniforme na agricultura. Para Sismondi, nem na agricultura nem na manufatura existe uniformidade da taxa de lucro, em virtude da mobilidade geográfica dos produtores agrícolas ser pequena e a mobilidade dos capitais manufatureiros ver-se tolhida pelo peso do capital fixo. 
- A suposição de taxa uniforme de lucro na agricultura permite a Ricardo “(...) reduzir o arrendamento à simples avaliação da diferença entre a faculdade produtiva das diversas terras." (Sismondi, 1819:250). Para Sismondi, a renda diferencial é somente um dos aspectos da renda da terra.

- Mais ainda, Sismondi critica Ricardo por desconsiderar qualquer outro sistema de exploração da terra que não o de grandes fazendas. Mesmo na Inglaterra, entende Sismondi, a pequena exploração familiar é importante.

- Havendo rendimento, o consumo decorrente impele à exploração de todas as terras. Portanto, não há terras livres ou terra (marginal) que possa ser utilizada sem o pagamento de renda. ${ }^{14}$

- O produto líquido é o que serve de base para fixar a renda. Mas essa categoria engloba rendimentos distintos, a saber: 1 . compensação do trabalho produtivo da terra, ou seja, da faculdade de gerar excedente; 2 . preço de monopólio; 3. renda diferencial devida aos diferenciais de produtividade; 4. renda dos adiantamentos primitivos. De acordo com Sismondi, o sistema de Ricardo considera somente os dois últimos rendimentos, ignorando os dois primeiros.

- Para Sismondi, não se pode assumir que o salário do trabalhador agrícola sempre permanece ao nível de subsistência. As condições de barganha do trabalhador oscilam conforme as condições do mercado - no caso, a relação entre braços disponíveis e terras a serem cultivadas. Sem pré-determinação do salário de subsistência, não há como definir de antemão a renda dos proprietários e o lucro dos capitalistas. Como foi visto, no sistema de Sismondi a distribuição de renda se mantém permanentemente aberta à barganha.

Em suma, na sua crítica à teoria ricardiana da renda, Sismondi não apenas demarca duas visões distintas de economia política, mas reafirma aspectos importantes de seu pensamento, particularmente a propensão a considerar a diversidade de relações sociais, a atenção à situação das classes trabalhadoras, a conexão entre produção, rendimentos e despesa. A crítica de Sismondi reforça ainda o papel do mecanismo de oferta e demanda na determinação dos preços e dos rendimentos, além de revelar pouco apreço pela noção de preço natural, no sentido utilizado por Adam Smith na Riqueza das Nações (1976).

Uma passagem do capítulo XIII do Livro Terceiro, que contém a crítica à concepção ricardiana da renda, resume bem o pensamento de Sismondi a respeito da distribuição do produto da agricultura e da formação de preços:

"Deste modo, o produto líquido da agricultura, ou a melhor-valia das colheitas sobre as reprises do trabalhador, é uma quantidade positi-

\footnotetext{
${ }^{14}$ Esse é um ponto central na crítica de Malthus à teoria ricardiana da renda.
} 
va, com o que a sociedade se enriquece, independentemente das variações do mercado; e ela fornece uma base real à renda das terras. Mas o valor mercantil deste produto pode ser fixado por uma luta dupla e até mesmo tripla, de modo que, de acordo com as circunstâncias, às vezes ela permanecerá inteiramente em mãos do proprietário, mesmo acrescida de um preço de monopólio; às vezes ela ficará em parte com o fazendeiro ou com o trabalhador, que fizeram nascer as colheitas; muitas vezes, enfim, o consumidor obterá a vantagem.” (Sismondi, 1819:233-234).

\section{CONCLUSÕES}

O ponto de partida do artigo foi a constatação de que Cantillon e Sismondi, dois autores que a uma primeira aproximação poderiam ser considerados malthuseanos, acabam, na análise da dinâmica populacional, por propor temas e enfoques diferenciados e razoavelmente afastados dos limites estritos do sistema de Malthus. Enquanto para Malthus o choque efetivo ou potencial entre população e meios de vida limita e molda de modo definitivo o entendimento da vida em sociedade e do funcionamento da economia, ${ }^{15}$ Cantillon e Sismondi transformam suas suaves versões da lei de população em um dos elementos de sistemas de economia política que são, a um mesmo tempo, diversificados entre si e contrastantes com o que se poderia denominar de padrão ricardiano (e, de certo modo, malthuseano) de determinação das relações entre salários e excedente. ${ }^{16}$ Deve-se reconhecer que um elemento comum a Cantillon, Sismondi e Malthus é a consideração de que a relação entre população e desenvolvimento econômico é um dos pontos vitais das visões de sistema econômico.

$\mathrm{Na}$ análise das relações entre economia e população, a questão de fundo nem é tanto o contraste entre o populacionismo e o anti-populacionismo, um tema que admite meios tons. ${ }^{17}$ A questão de fundo se evidencia no fato de que Cantillon e Sismondi abriram novas perspectivas para o entendimento das relações en-

\footnotetext{
${ }^{15}$ Para Malthus, vale sempre a idéia de que “(...) como, por aquela lei de nossa natureza que faz a alimentação necessária à vida do homem, a população nunca pode realmente aumentar além do nível mínimo de nutrição capaz de sustentá-la, um forte obstáculo à população, decorrente da necessidade de obter comida, tem que estar constantemente em operação.” (Malthus, 1803:6).

${ }^{16}$ Sempre de acordo com a interpretação de Sraffa (1951) e de diversos intérpretes pós-sraffianos, entre os quais Garegnani (1983) e Roncaglia (1985). No que se refere a outros autores - Cantillon e Sismondi inclusive -, acredito que o presente artigo coloca em dúvida a extensão em que se deve aplicar a concepção ricardiana de salário de subsistência e de independência entre valor e distribuição.

${ }^{17}$ Nem mesmo autores tidos como anti-populacionistas sem arestas, como Quesnay e Malthus, viram na população um mal. Quesnay desejava simplesmente mostrar que o relevante na formação de riqueza era o trabalho assistido por capital; o próprio Malthus é hoje admitido como um autor preocupado sobretudo com o bem-estar da população e com a promoção dos contingentes pobres. Sobre o anti-populacionismo de Quesnay, Coutinho (1993); sobre Malthus, Winch (1987) e Pullen (1989).
} 
tre economia e população, mesmo tendo aderido à proposição de que o tamanho da população é função da disponibilidade de meios de vida.

Em Cantillon, essas novas perspectivas incluem como tópicos de destaque:

- A atenção especial concedida à mobilidade da população. Em diversas circunstâncias, a mobilidade populacional funciona como uma variável de ajuste nos mercados de trabalho, de bens e, inclusive, de capitais;

- A proposição de que a demanda por mão-de-obra determina o número de trabalhadores empregados nas diversas qualificações. A rigor, as decisões de cultivo determinam a demanda por mão-de-obra e combinam-se com a produção de alimentos que é necessária ao sustento dessa população;

- A preferência por mecanismos suaves, "preventivos”, de ajustamento entre população e meios de subsistência;

- A introdução da dimensão locacional e geográfica na análise da dinâmica populacional. Essa dimensão, de grande originalidade, complementa o tratamento da mobilidade:

Já em Sismondi, os tópicos mais relevantes são:

- A possibilidade de que a dinâmica populacional veja-se afetada pelos problemas de concatenação entre rendimentos e despesas, que emanam do circuito de reprodução do capital. Os problemas de concatenação podem afetar os lucros e a acumulação;

- A atenção às relações sociais e, particularmente, aos diversos quadros institucionais nos quais se dá a exploração agrícola. Cada relação social, graças aos incentivos que provê, implica potenciais diversos de crescimento econômico e populacional, bem como padrões de subsistência variados para a população trabalhadora. As relações sociais incidem sobre a dinâmica populacional pelos dois lados: expansão dos salários e expansão da produção (o que também afeta o mercado de trabalho);

- O papel irrelevante concedido à mobilidade, seja da população, seja do capital, como mecanismo de ajuste nos mercados e de nivelação das taxas de salário e de lucro.

Esse último tópico - o papel da mobilidade e a formação (ou não) de taxas uniformes de remuneração - revela uma diferença substancial entre os sistemas de Cantillon e de Sismondi. O Ensaio é uma obra onde os mecanismos de mercado têm dimensão preponderante e sempre ajustam os preços de mercado aos "preços normais". Esses mecanismos produzem os ajustamentos nos mercados de trabalho e de capital que levam à formação de taxas de lucro e salariais uniformes, observadas as diferenças de qualificação da mão-de-obra e de risco associada às aplicações de capital. Em Cantillon, os preços normais de longo prazo são uma idéia subjacente. O processo de ajustamento aos preços normais envolve a mobilidade dos capitais e da mão-de-obra. 
Sismondi, contrariamente a Cantillon, nem sempre acredita nos ajustamentos de mercado. No seu sistema, mão-de-obra e capital são menos móveis. Podese dizer que os Novos Princípios dão mais espaço às diferenças (nos salários, nas relações sociais, nas aplicações de capital...) do que às semelhanças. Curiosamente, nesse estrito sentido, Sismondi aproxima-se de Malthus, enquanto Ricardo aproxima-se de Cantillon.

No que se refere à preponderância assumida pela produção agrícola, os dois autores convergem, a despeito das grandes diferenças de pano de fundo de seus sistemas. Quanto a isso, enquanto Cantillon filia-se a um naturalismo agrícola bastante difundido no século XVIII, Sismondi tem como ponto de referência a degradação do trabalho manufatureiro e os efeitos da concentração de capital. Sismondi, aliás, critica abertamente a versão fisiocrática de produtividade exclusiva do trabalho agrícola.

A despeito das diferenças de pano de fundo, é comum aos dois autores o entendimento de que a subsistência representa o pilar central da atividade econômica. Tanto no Ensaio quanto nos Novos Princípios, a agricultura tem um papel dominante. Nesta última obra está presente, como um viés suplementar, a consideração de que a demanda por alimentos é garantida em função da conexão entre rendimentos e despesas, um ponto em que Sismondi aproxima-se do Malthus dos Principles of Political Economy (1820).

O tratamento concedido à fixação dos salários ao nível de subsistência e à própria formação da cesta de subsistência é outra questão-chave. Esse é um tema recorrente na economia política dos séculos XVII, XVIII e XIX, o que em parte se explica pela realidade econômica e demográfica da época de surgimento do capitalismo - a existência de uma população pobre numerosa e, portanto, de uma pressão de oferta nos mercados de trabalho -, em parte por uma exigência de sistema: sem a fixação de uma cesta de subsistência, a distribuição de renda e o excedente econômico ficam indeterminados. É lícito nessa medida incluir Cantillon e Sismondi no grupo de autores que entenderam a economia como uma investigação sobre o excedente, condicionada pela noção de salário de subsistência. Além disso, Cantillon e Sismondi compartilharam o entendimento de que a determinação do padrão de subsistência é um processo amplo, envolvendo fatores históricos e culturais.

Aqui cessam as semelhanças e começam as diferenças. Em Cantillon, a noção de subsistência adquire uma certa indeterminação, ao incluir os fazendeiros e os trabalhadores/produtores manufatureiros. Cantillon não só admite uma escala de subsistência em conformidade com a afluência do "trabalhador", como considera a renda de pessoas que têm em sua remuneração o risco como um elemento palpável uma renda de subsistência. ${ }^{18}$

Em Sismondi, a noção de salário de subsistência é bastante abalada pela in-

${ }^{18}$ Foi justamente para fugir dessa indiferenciação que Adam Smith veio a repisar, na Riqueza das $\mathrm{Na}$ ções (1776), que o lucro é uma remuneração exclusiva do capital, e não um "salário de supervisão". 
sistência em considerar que, afinal, as condições dos trabalhadores não precisariam ser tão dramáticas. Para os trabalhadores urbanos e rurais, isso implica remuneração acima do nível de subsistência - e não, de modo claro, um alargamento do padrão de subsistência. Como foi visto, o excesso de oferta de mão-de-obra (em parte decorrente da lei de população) em princípio impede os trabalhadores manufatureiros de manterem esse padrão mais elevado. Já os trabalhadores rurais podem manter um padrão de consumo mais elevado — ou adquirir uma remuneração acima do padrão de subsistência? - , em relações sociais determinadas. Enfim, a despeito da lei de população, os mecanismos de ajustamento da economia não necessariamente fixam o salário do trabalhador ao nível de subsistência.

Nos dois autores, a relativa indeterminação da subsistência, que se dá por razões diferentes, impede uma fixação não-ambígua do lucro, ou do excedente sobre a subsistência. O lucro não emerge como uma categoria dotada de leis próprias, objetivamente estabelecidas. Esta conclusão aplica-se com menos força a Cantillon do que a seus sucessores fisiocratas, porque a identificação de uma "terceira renda", assim como a importância atribuída ao risco, apontam para a existência do lucro como uma categoria à parte. Ainda assim, a determinação do lucro fica no Ensaio embaralhada pela imprecisão da parcela que corresponde à subsistência.

Já nos Novos Princípios o quadro é bem outro. Estamos diante de uma teoria dos rendimentos que se aproxima em muitos aspectos da idéia de remuneração dos fatores conforme sua contribuição, de Say. Como conciliar salário de subsistência com remuneração conforme a contribuição dos fatores é outra história, mas aqui temos uma dubiedade típica do sistema de Sismondi.

Em uma formulação sintética, pode-se afirmar que a noção de excedente econômico está presente em Cantillon e em Sismondi, enquanto que a determinação desse excedente por leis objetivas e/ou por uma combinação de hábitos sociais e condições de produção, é bem menos clara. Nesse ponto, os dois autores afastam-se tanto da tradição de Ricardo como do próprio Malthus.

\section{REFERÊNCIAS BIBLIOGRÁFICAS}

BREWER, A.(1992) Richard Cantillon - Pioneer of Economic Theory. London: Routledge, 1992.

CANTILLON, R.(1755) Essay on the Nature of Commerce in General. London, Transaction Publishers, 2003. Primeira edição em francês, 1755.

CARTELIER, J.(1981). Excedente y Reproducción: la formación de la economia política clasica. Mexico: Fondo de Cultura Economica, 1981.

COUTINHO, M.(2005). “Espaço e Economia no Sistema de Cantililon”. In: Nova Economia, vol. 15, n. 1, Belo Horizonte, 2005.

COUTINHO, M.(1993) Lições de Economia Política Clássica. São Paulo: Hucitec, 1993.

GAREGNANI, P.(1983) "Ricardo's Early Theory of Profits and its Rational Foundation: A Reply to Professor Hollander". In: Cambridge Journal of Economics, Cambridge, 7, 1983.

MALTHUS, T.(1803) An Essay on the Principle of Population. London: Dent, 1973. Segunda edição, 1803. 
MALTHUS, T.(1820) Principles of Political Economy. Cambridge: Cambridge University Press, 1989. Primeira edição, 1820.

PULLEN, J.(1989). "Introduction to the Variorum Edition”. In: Malthus, T. R. Principles of Political Economy, vol. 1. Cambridge: Cambridge University Press, 1989.

RONCAGLIA, A.(1985). "Hollander's Ricardo". In: Caravale (ed). The Legacy of Ricardo. Oxford, Basil Blackwell, 1985.

SISMONDI, Sismonde de (1819) Nouveaux Principes d'Économie Politique. Paris: Calmann-Levy, 1971. Primeira edição, 1819.

SMITH, A.(1776) An Inquiry into the Nature and Causes of the Wealth of Nations. Indianapolis, Liberty Fund, 1981. Primeira edição, 1776.

SRAFFA, P.(1951). “Introduction to Ricardo's Principles of Political Economy”. In: Ricardo, Works and Correspondence of David Ricardo, vol. 1. Cambridge: Cambridge University Press, 1981. Primeira edição, 1951.

TARASCIO, V.(1991) “Cantillon's theory of population size and distribution”. In: Blaug, M. (ed). Richard Cantillon (1680-1734) and Jacques Turgot (1727-1781). Aldershot: Edward Elgar, 1991.

WINCH, D.(1987) Malthus. Oxford: Oxford University Press, 1987. 